\title{
INFLUÊNCIA DO GRAU DE CORROSÃO DAS ARMADURAS NA EFICIÊNCIA DO MÉTODO DE REALCALINIZAÇÃO PARA TRATAMENTO DE ESTRUTURAS DE CONCRETO CARBONATADAS
}

\author{
P. R. R. FERREIRA ${ }^{1}$, G. R. MEIRA ${ }^{1,{ }^{*}}$, D. C. BARBOSA ${ }^{1}$, M. CARVALHO ${ }^{1}$, J. ANDRADE $^{1}$ \\ Instituto Federal de Educação, Ciência e Tecnologia da Paraíba ${ }^{1}$ \\ gibsonmeira@yahoo.com*
}

Submetido 05/03/2017 - Aceito 22/11/2017

DOI: $10.15628 /$ holos.2017.5735

\section{RESUMO}

O tratamento por realcalinização é um dos métodos aplicados para o restabelecimento das condições de alcalinidade da matriz cimentícea e, consequentemente, para alcançar a possível repassivação da armadura, sem uma ação destrutiva significativa sobre a estrutura. Este artigo analisa a eficiência da realcalinização na repassivação de armaduras com diferentes períodos de exposição a meio carbonatado. Para tal, armaduras para concreto armado, com diâmetro de $6.3 \mathrm{~mm}$, foram imersas em uma solução saturada de hidróxido de cálcio, simulando a solução dos poros do concreto. Após um período de 17 dias, essas soluções foram carbonatadas com uma mistura de $5 \%$ de $\mathrm{CO} 2$, até a solução atingir um $\mathrm{pH}$ próximo a 8,5. Uma vez iniciado o processo de corrosão, as células ficaram em ambiente de laboratório por um período de 7, 28 e 90 dias, de modo a atingir diferentes graus de corrosão. Após isso, as soluções foram realcalinizadas através da troca das soluções carbonatadas por soluções novas. Durante todos esses períodos, as armaduras foram monitoradas através de medidas eletroquímicas empregando a técnica de resistência de polarização linear. As medidas eletroquímicas mostram os momentos em que as armaduras despassivaram, bem como os momentos em que essas apresentaram uma condição de restabelecimento das condições de passividade ou não. O período de exposição mais longo a meio carbonatado dificultou a repassivação das armaduras.

PALAVRAS-CHAVE: Carbonatação, concreto armado, realcalinização, repassivação.

\section{INFLUENCE OF CORROSION DEGREE OF REINFORCEMENT ON EFECTIVENESS OF REALKALISATION METHOD FOR TREATING CARBONATED CONCRETE STRUCTURES}

\begin{abstract}
The realkalisation treatment is one of the methods applied to recover the alkalinity conditions of cementitious matrix and, consequently, to meet the possible reinforcement repassivation without any significant destructive procedure to structure. This paper analyses the effectiveness of realkalisation on repassivation of reinforcements with different exposure times on carbonated media. For this purpose, concrete reinforcements with $6.3 \mathrm{~mm}$ core were immersed in saturated solution of calcium hydroxide, simulating the concrete porous network solution. After 17 days, these solutions were carbonated with a $5 \% \mathrm{CO} 2$ mixture until reaching a $\mathrm{pH}$ close to 8,5 . After starting the corrosion
\end{abstract}

process, the cells remained in laboratory environment for 7, 28 and 90 days to meet different corrosion degrees. Afterwards, the carbonated solutions were realkalised by changing the solutions for new ones. Reinforcements were monitored throughout all these periods by electrochemical measurements using the linear polarization resistance technique. Electrochemical measurements show the moments in which reinforcements depassivated, as well as the moments in which they recovered or not the passivity condition. The longer exposure to carbonated media made difficult the reinforcement repassivation.

KEYWORDS: Carbonatation, reinforced concrete, realkalisation, repassivation. 


\section{INTRODUÇÃO}

Estruturas de concreto armado estão expostas aos mais diversos tipos de ambiente. Entre eles, ambientes de atmosfera urbana contribuem para o desenvolvimento da corrosão de armaduras causada pela carbonatação do concreto (BERTOLINI et al., 2008). A carbonatação do concreto é consequência da reação entre o $\mathrm{CO}_{2}$ contido na atmosfera e os componentes alcalinos da pasta de cimento. Esta reação conduz a uma diminuição do $\mathrm{pH}$ da fase líquida do concreto e, em certas condições de umidade e temperaturas, induz a armadura a corrosão (CASCUDO, 1997).

O concreto é um material com elevados valores de $\mathrm{pH}$, algo entre 12,5 e 13,5 (MEHTA e MONTEIRO, 2008). Essa elevada alcalinidade do concreto proporciona a formação e a estabilidade de uma película passivadora, composta por uma camada de óxidos muito fina e aderida fortemente à superfície do aço. Essa película protege a armadura de corrosão posterior (ELSENER, 2001; BERTOLINI et al., 2008).

Uma vez que a frente de carbonatação atinja a armadura e as condições de alcalinidade do concreto estejam abaixo de 11,5, faz-se importante recuperar a alcalinidade da solução contida nos poros do concreto de modo a prevenir e, até certo ponto, tratar a corrosão (MIETZ, 1998). Duas técnicas de realcalinização foram desenvolvidas com esse intuito, a realcalinização eletroquímica e a realcalinização passiva ou natural.

No primeiro caso, a alcalinidade é proporcionada no interior do concreto, por meio da aplicação de um campo elétrico entre a armadura e uma malha externa temporária (MIETZ, 1998). O tratamento por realcalinização eletroquímica foi desenvolvido na década de 1980, para tentar recuperar estruturas de concreto armado afetadas pela carbonatação. Pocock (1994) apresentou uma visão geral da técnica eletroquímica, como uma opção de recuperação alternativa e Mietz (1998) apresentou um estudo sobre o estado da arte dos métodos de reabilitação eletroquímicos para estruturas de concreto armado.

O método de realcalinização natural baseia-se na aplicação de um revestimento altamente alcalino na superfície do concreto, como, por exemplo, um revestimento confeccionado de cimento Portland. Neste caso, a alcalinidade é reestabelecida lentamente através da difusão iônica dos componentes alcalinos através do concreto (ARAUJO, 2009).

Grande parte dos estudos científicos sobre realcalinização foram realizados com o objetivo de entender as características dos fenômenos envolvidos (ELSENER, 2001; BERTOLINI et al., 2008). Outros trabalhos relacionam os efeitos do método de tratamento com as alterações nas características micro-estruturais, com o comportamento do método em função de características do material, do tipo de cimento e da relação agua/cimento (ARAUJO, 2009; RIBEIRO et al., 2013).

Entretanto, poucos estudos foram desenvolvidos acerca da eficiência do método e seu comportamento a longo prazo. Destaca-se o trabalho de Tong et al. (2011), no qual os autores buscaram estudar a eficiência do método de realcalinização eletroquímica, mas não conseguiram visualizar a repassivação da armadura nas leituras eletroquímicas e, sim, uma redução drástica na taxa de corrosão. Já Yein e Chang (2005) observaram que o potencial de corrosão em circuito aberto é reestabelecido com sucesso e, consequentemente, a película passivadora seria novamente formada. 
Outros pesquisadores também questionam a eficácia do tratamento de realcalinização em relação à repassivação da armadura (BASTIDAS et al., 2008; MIRANDA et al., 2006). A partir deste cenário de incertezas pode-se observar que ainda não há um consenso na comunidade acadêmica sobre esse aspecto de vista e que mais pesquisas são necessárias para elucidá-lo.

É nesse meio que este trabalho se insere, buscando analisar a eficiência do método de realcalinização para tratamento de estruturas de concreto armado carbonatadas, através do monitoramento de variáveis eletroquímicas que envolvem o processo de corrosão.

\section{METOdOLOGIA}

Para o presente trabalho foram vencidas quatro etapas, as quais correspondem à limpeza das barras e preparação das células de ensaio, as condições de carbonatação acelerada, o procedimento para tratamento por realcalinização e o monitoramento eletroquímico usado durante todo o processo.

\subsection{Limpeza das barras e preparação das células de ensaio}

Antes da confecção das células de ensaio, as barras foram submetidas a um processo de decapagem química. A limpeza química das barras seguiu as recomendações da norma ASTM G1 (2011), a qual foi realizada de acordo com a seguinte sequência: corte das barras no tamanho de $100 \mathrm{~mm}$, chanfro nas pontas com um esmeril, disposição das barras em solução de ácido clorídrico na proporção de 1:1 e 3,5 g/l de hexametilenotetramina por quinze minutos, lavagem e escovação imediata com escova de cerdas plásticas em água corrente para retirada final da camada de óxido, imersão total em acetona por dois minutos para desengordurar e facilitar a secagem e secagem com ar quente.

Em seguida, as barras foram pintadas com resina epóxi, deixando apenas uma longitude de exposição de $30 \mathrm{~mm}$. Depois de endurecida a resina, as barras foram submetidas novamente à limpeza química, conforme descrito acima. Para auxiliar a realização do procedimento de limpeza química fez-se uso de um banho ultrassônico da Ecosonics (Figura 1). Após a segunda decapagem, as barras foram submetidas imediatamente à solução saturada de hidróxido de cálcio.

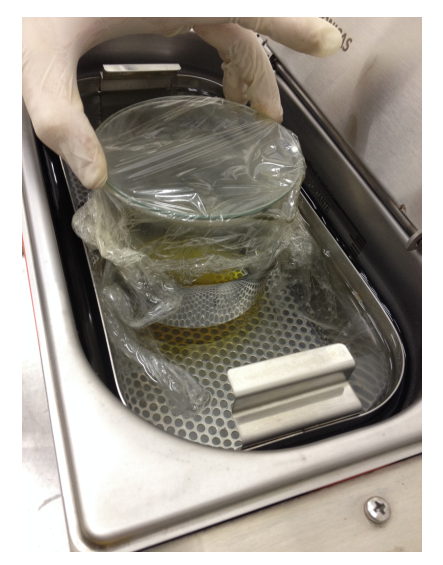

Figura 1: Limpeza química das barras. 
As células de ensaio (CE) empregados nesse trabalho consistiram no emprego de barras de aço imersas em solução alcalina e contra eletrodo de grafite, conforme disposição apresentada na Figura 2. Tal configuração é utilizada há mais de 50 anos (KAESCHE, 1959), com intuito de simular a fase aquosa presente nos poros do concreto (CASCUDO, 1997; MOREIRA, 2006; BASTIDAS et al., 2008).

As barras empregadas foram de aço CA-50, com bitola de $6,3 \mathrm{~mm}$ e comprimento de 100 $\mathrm{mm}$. A solução empregada para simular a fase líquida do concreto foi uma solução de hidróxido de cálcio saturado, preparada com água deionizada e com pH de aproximadamente 12,6. A escolha pelo hidróxido de cálcio se deu por este ser um dos principais produtos das reações de hidratação do cimento, e um dos responsáveis pela alta alcalinidade do concreto nas primeiras idades (CASCUDO, 1997; MEHTA e MONTEIRO, 2008).

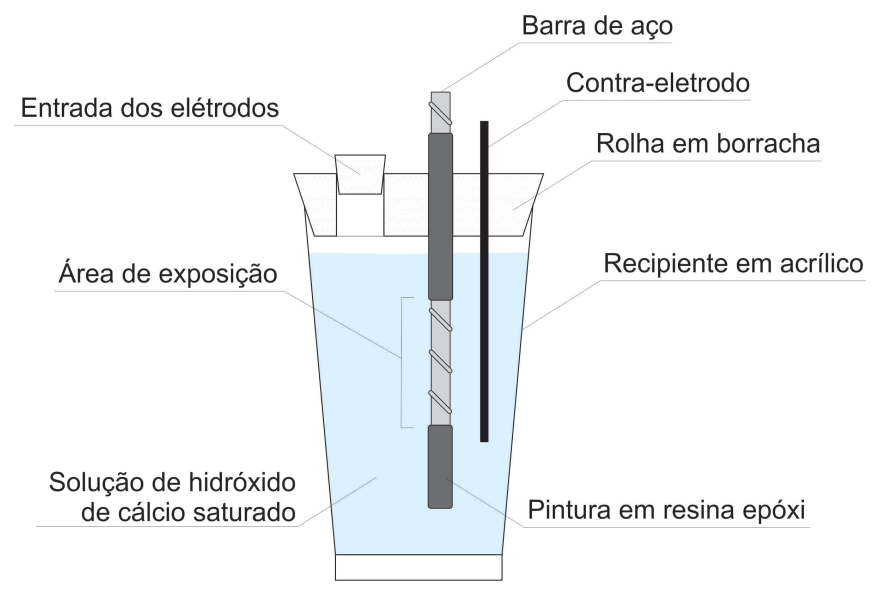

Figura 2: Configuração das células de ensaio.

Foram produzidas seis CE para cada período de aceleração da corrosão após carbonatação. Durante todo esse período, as CE foram mantidas em ambiente de laboratório (UR $=70 \pm 10 \%$ e T $=20 \pm 5$ 으) .

\subsection{Carbonatação acelerada e aceleração da corrosão}

A carbonatação da solução empregada nas células de ensaio aconteceu através da inserção de gás carbônico $\left(\mathrm{CO}_{2}\right)$ na solução, a uma concentração de $5 \%$.

Durante o processo de carbonatação da solução, o pH da solução foi monitorado constantemente através de um pHmetro de bancada (Figura 3(b). Ao serem atingidas medidas de pH próximo a 8,5, cessava a inserção do gás. Após a carbonatação da solução, as armaduras foram monitoradas por medidas eletroquímicas, conforme descrito no item 2.4.

Com o intuito de avaliar a eficiência do método de realcalinização para armaduras com determinado grau de corrosão, uma vez detectado o início do processo de corrosão, as armaduras ficaram em solução carbonatada durante sete, vinte e oito e noventa dias. Finalizado essa etapa, as barras foram submetidas ao processo de tratamento por realcalinização. 


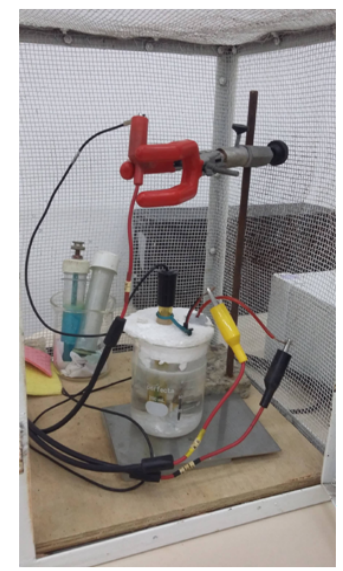

a)

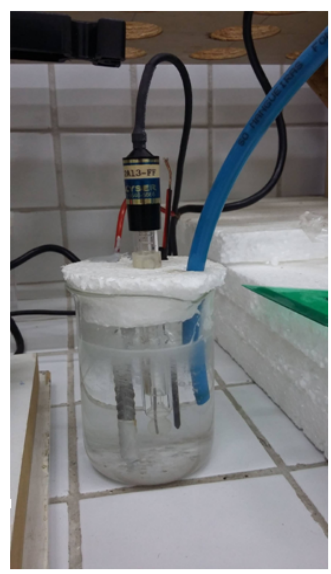

b)

Figura 3: a) Monitoramento eletroquímico das células; b) carbonatação das soluções.

\subsection{Processo de tratamento por realcalinização}

O método de tratamento adotado foi a realcalinização natural por substituição total da solução carbonatada. Ele consiste na troca total da solução carbonatada, onde está contida a armadura em processo de corrosão, por uma solução virgem de hidróxido de cálcio saturado $\left(\mathrm{Ca}(\mathrm{OH})_{2}\right)$, objetivando a reinstalação das condições iniciais de $\mathrm{pH}$ do meio. Uma vez realizado o processo de tratamento da corrosão por realcalinazação, as armaduras foram monitoradas eletroquimicamente para analisar a eficiência do método em relação à repassivação da armadura.

\subsection{Monitoramento eletroquímico}

O monitoramento das barras, nas $\mathrm{CE}$, foi realizado através da técnica eletroquímica de resistência de polarização, com compensação da queda ôhmica, com medidas do potencial de corrosão em circuito aberto e densidade de corrente instantânea de corrosão. $O$ equipamento empregado nas leituras foi um ponteciostato de bancada, modelo GILL AC da ACM Instruments.

Para a realização das medidas, foi empregado um eletrodo de referência de $\mathrm{Ag}-\mathrm{AgCl} \mid \mathrm{KCl}$ (1M) e um contra eletrodo de grafite, mantendo-se todo o conjunto envolto em uma gaiola de Faraday, para evitar interferências externas (Figura 3(a). A técnica de resistência de polarização (Rp) tem sido amplamente empregada na literatura, com o objetivo de detecção da despassivação das armaduras e estudos sobre o teor crítico de cloretos (ANGST \& VENNESLAND, 2008; MEIRA et al., 2014) e alia uma resposta eficiente em relação à identificação da instalação do processo de corrosão com a rapidez das medidas. Esses foram os motivos de sua adoção no presente estudo.

As leituras foram realizadas em intervalos constantes durante a etapa inicial de estabilização da película de passivação, durante a carbonatação e aceleração da corrosão e após a realcalinização das soluções. Leituras de potencial de corrosão mais eletronegativas que - $256 \mathrm{mV}$ $(\mathrm{Ag} \mid \mathrm{AgCl})$ e densidade de corrente superiores a $0,1 \mu \mathrm{A} / \mathrm{cm}^{2}$, foram empregadas como critérios para identificar o momento da despassivação, conforme recomenda a literatura (CASCUDO, 1997). 


\section{RESULTADOS}

\subsection{Monitoramento eletroquímico}

Nesta seção, são apresentados os resultados de monitoramento eletroquímico das CEs. As variáveis estudadas foram o potencial de corrosão e a densidade de corrente de corrosão. 0 potencial de corrosão empregou faixas de classificação de probabilidade de corrosão de acordo com a norma ASTM C-876 (2009) e a densidade de corrente utilizou a classificação de nível de corrosão proposta por Cigna et al. (1997).

As Figuras de 4 a 6 mostram os resultados das leituras do potencial de corrosão para as CE com 7, 28 e 90 dias de corrosão após a carbonatação, respectivamente.

Os resultados mostram, em sua grande maioria, que as leituras inicias (nos primeiros cinco dias) do potencial de corrosão indicam um risco incerto de corrosão. Porém, estes resultados vão se tornando mais eletropositivos com o passar do tempo, indicando leituras que se aproximam da condição de um baixo risco de corrosão.

Uma vez carbonatada a solução, as leituras do potencial de corrosão tendem a apresentar uma mudança significativa de comportamento, com uma queda considerável para patamares que indicam uma alta probabilidade de corrosão. Após a recomposição do pH da solução, ou seja, com a aplicação do tratamento, as leituras tenderam a apresentar uma retomada das condições iniciais deste parâmetro eletroquímico, com exceção das CEs com 90 dias de corrosão após a carbonatação.

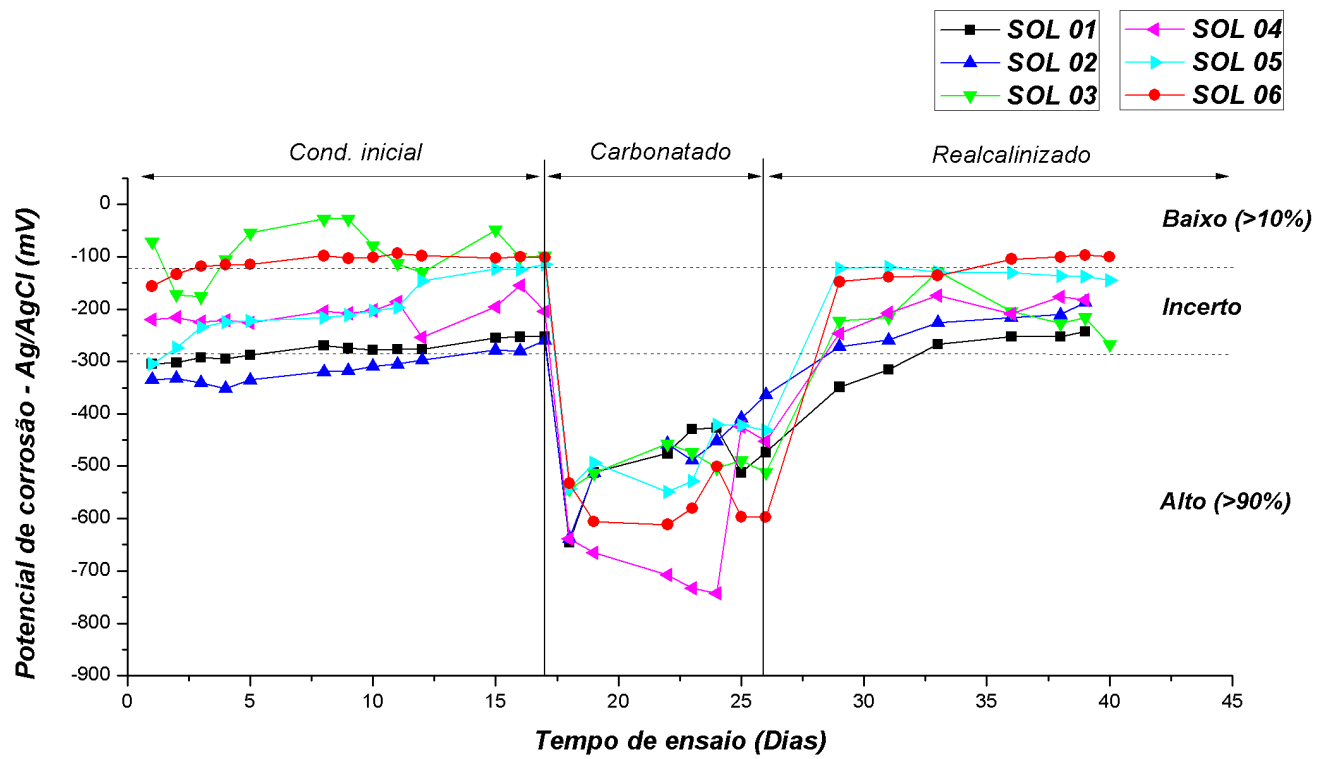

Figura 4: Evolução, ao longo do tempo, do potencial de corrosão para as CE com 7 dias de corrosão pós carbonatação. 


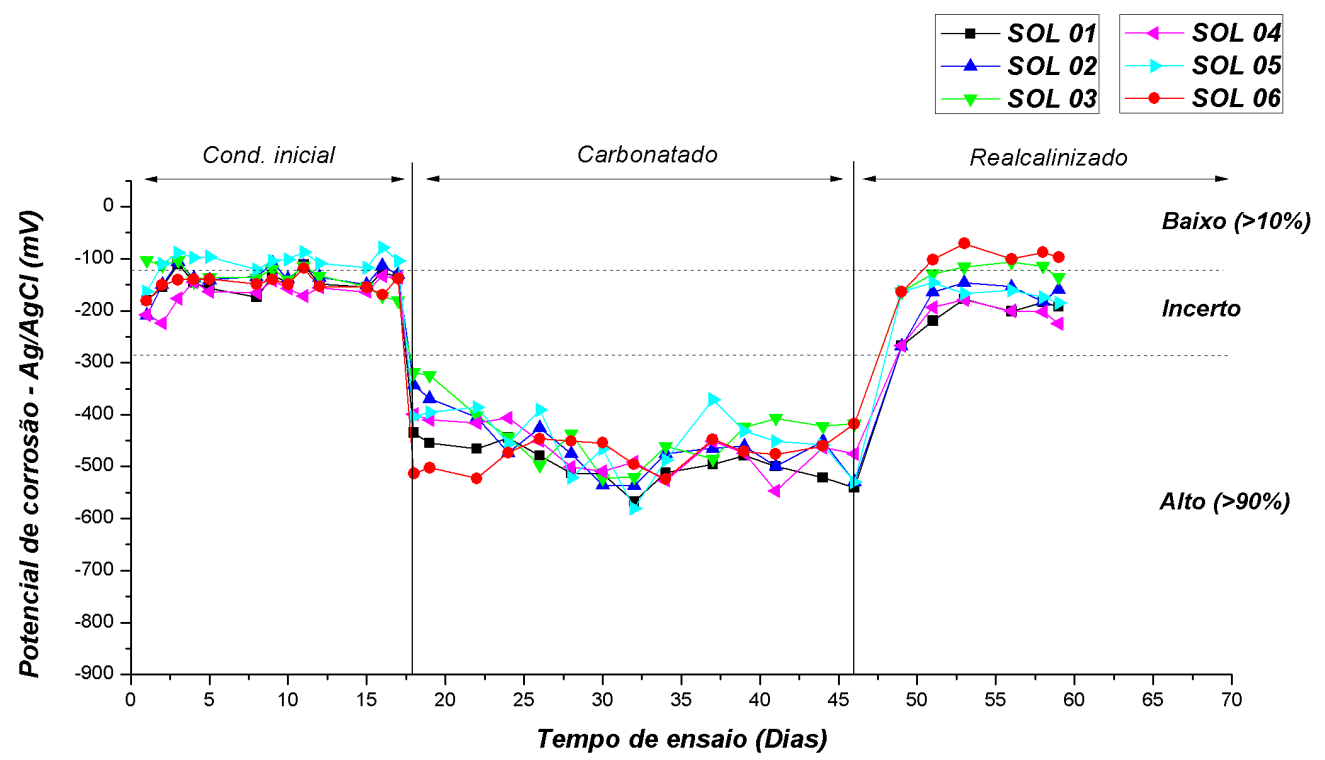

Figura 5: Evolução, ao longo do tempo, do potencial de corrosão para as CE com 28 dias de corrosão pós carbonatação.

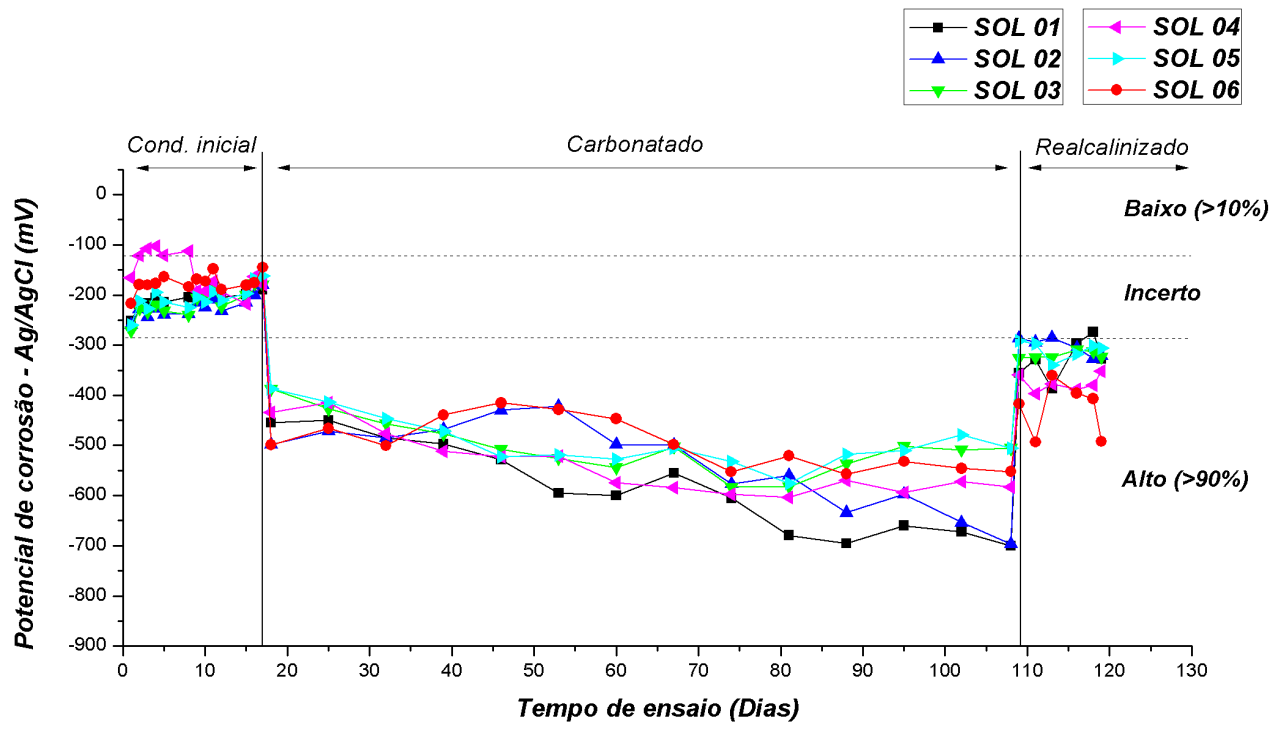

Figura 6: Evolução, ao longo do tempo, do potencial de corrosão para as CE com 90 dias de corrosão pós carbonatação.

Tendo em vista a densidade de corrente de corrosão, as Figuras de 7 a 9 mostram os resultados deste parâmetro eletroquímico para as CEs com as mesmas idades apresentadas para o potencial de corrosão.

Assim como para o potencial de, as medidas de densidade de corrente de corrosão mostram um baixo nível de corrosão para as armaduras nas idades iniciais. Uma vez carbonatadas as soluções, os valores da densidade de corrente de corrosão tenderam a apresentar altos valores dessa variável, passando de patamares médios entre 0,03 e $0,13 \mu \mathrm{A} / \mathrm{cm}^{2}$ para valores entre 3 e 6 $\mu \mathrm{A} / \mathrm{cm}^{2}$. 
Os resultados da corrente de corrosão mostram também que, com o tratamento empregado, as armaduras tendem a reduzir seus valores até certos níveis, isso para todas os períodos de corrosão pós carbonatação. Porém, as armaduras com 90 dias de solução carbonatada apresentaram patamares de densidade de corrente de corrosão ainda elevados, mesmo havendo uma redução deste patamar.

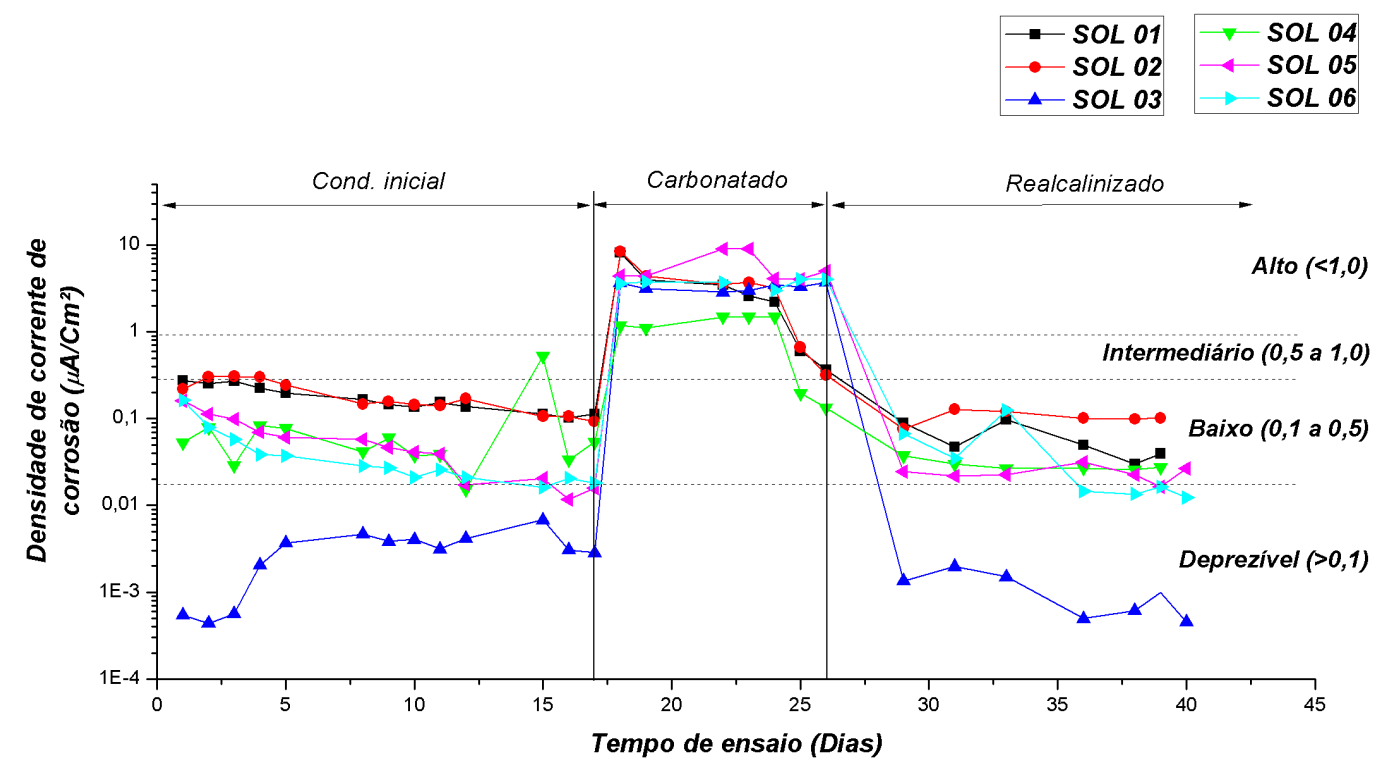

Figura 7: Evolução, ao longo do tempo, da densidade de corrente de corrosão para as CE com 7 dias de corrosão pós carbonatação.

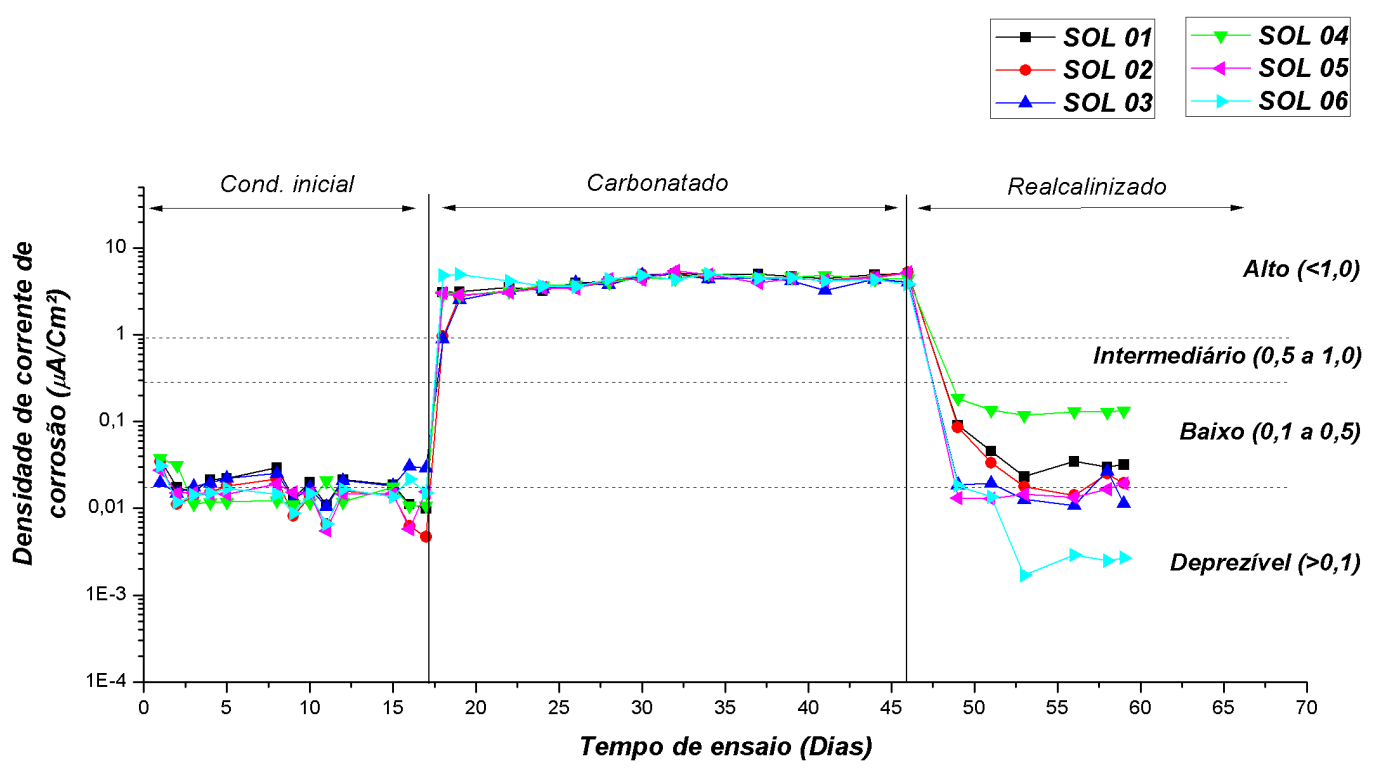

Figura 8: Evolução, ao longo do tempo, da densidade de corrente de corrosão para as CE com 28 dias de corrosão pós carbonatação. 


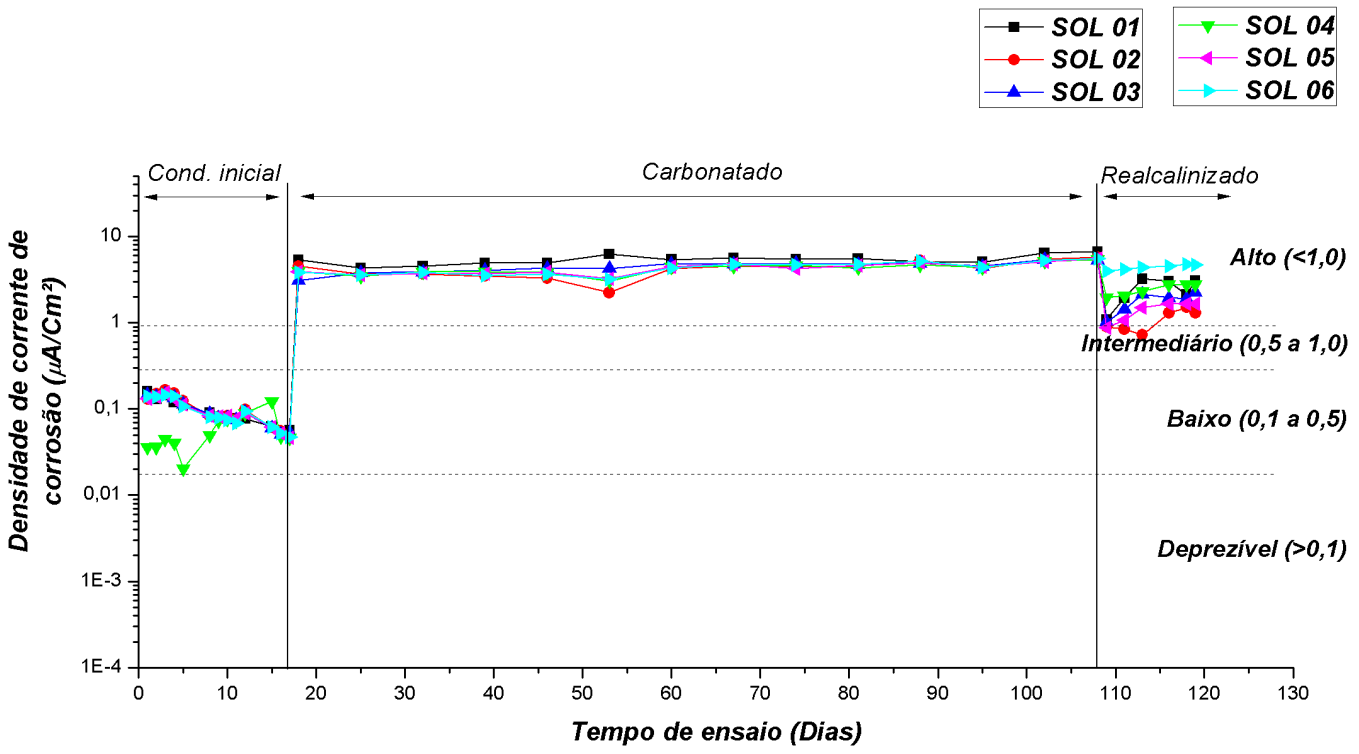

Figura 9: Evolução, ao longo do tempo, da densidade de corrente de corrosão para as CE com 90 dias de corrosão pós carbonatação.

\section{$3.2 \mathrm{pH}$ das soluções}

A Tabela 1 mostra a média dos resultados de $\mathrm{pH}$ das soluções, medido em cada CE e considerando o período de tempo em que a solução ficou carbonatada. Os resultados mostram que a carbonatação da solução reduziu em cerca de $30 \%$ o pH da solução para qualquer período de corrosão e a aplicação do tratamento tende a reestabelecer as condições de alcalinidade iniciais.

Tabela 1: pH médio das soluções em função do período de corrosão e etapa dos ensaios.

\begin{tabular}{c|c|c|c}
\hline \multirow{2}{*}{$\begin{array}{c}\text { Período de corrosão } \\
\text { após a carbonatação }\end{array}$} & \multicolumn{3}{|c}{ Condições de $\mathrm{pH}$ da solução } \\
\cline { 2 - 4 } & Inicial & Carbonatada & Realcalinizada \\
\hline 7 dias & $12,17 \pm 0,11$ & $8,84 \pm 0,51$ & $12,54 \pm 0,16$ \\
\hline 28 dias & $12,14 \pm 0,12$ & $8,88 \pm 0,41$ & $12,13 \pm 0,08$ \\
\hline 90 dias & $12,15 \pm 0,06$ & $8,53 \pm 0,42$ & $12,08 \pm 0,05$ \\
\hline
\end{tabular}

\section{ANÁLISE DOS RESULTADOS}

Por meio do monitoramento eletroquímico, foi possível observar que as barras tiveram comportamentos iniciais bastante parecidos para todas as idades, ou seja, os potenciais de corrosão e densidade de corrente dos CP assumiram valores iniciais de potencial um pouco mais eletronegativos e valores de corrente levemente mais elevados. Contudo, conforme decorria o tempo, as barras em solução alcalina possivelmente avançaram no período de formação da película passivadora, o que aumentou seus potenciais de corrosão e reduziu a densidade de 
corrente de corrosão. Esse processo de formação da película passivadora e estabilização das medidas eletroquímicas aconteceu em até quinze dias.

Realizada a carbonatação da solução, foi possível detectar que as barras apresentaram parâmetros eletroquímicos que demonstravam um estado de despassivação e o desenvolvimento do processo corrosivo. A Figura 10 mostra o processo de corrosão em armadura após 28 dias em solução carbonatada, com a formação de produtos da corrosão.

Uma vez que as condições de pH da solução foram restabelecidas, percebeu-se que os parâmetros eletroquímicos sofreram alteração, retomando as condições inicias para armaduras expostas a solução carbonatada em até 28 dias. Alguns autores afirmam que o aumento do pH em conjunto com um aumento das concentrações de metais alcalinos são indicadores suficientes para repassivação (ELSENER, 2001). No entanto, isso não se confirmou para todos os períodos de aceleração da corrosão aqui estudados.

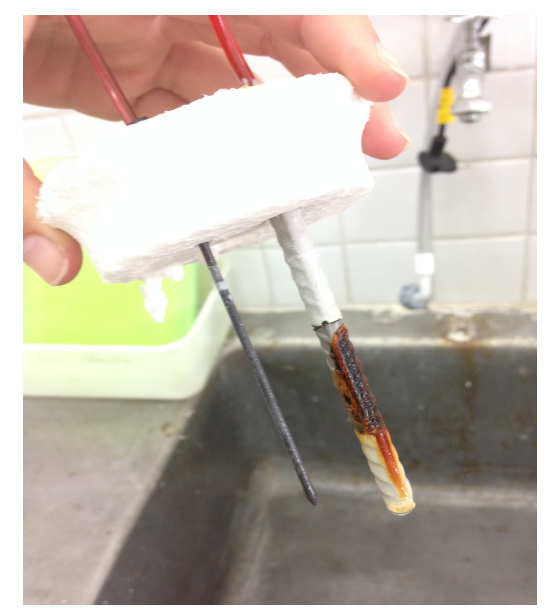

Figura 10: Detalhe da formação dos produtos da corrosão na armadura, após 28 dias em solução carbonatada.

Em um estudo realizado por Elsener (2001), o potencial de corrosão em circuito aberto de uma estrutural real de concreto armado sujeito a um processo de realcalinização eletroquímica [utilizando uma solução de 1 molar de carbonato de sódio $\left(\mathrm{Na}_{2} \mathrm{CO}_{3}\right)$ como solução, aplicando uma densidade de corrente de $200 \mathrm{~mA} / \mathrm{cm}^{2}$ durante 12 dias, seguida de 1 mês de despolarização), obteve, com o processo de tratamento, uma estabilização no valor de potencial em torno de -170 $\mathrm{mV}$ (ECS).

Yeih e Chang (2005), em seu estudo de laboratório com espécimes de concreto armado em processo de realcalinização eletroquímica, utilizando uma solução 1 molar de carbonato de sódio, aplicando uma densidade de corrente de $2,4 \mathrm{~mA}$.dia $/ \mathrm{cm}^{2}$ durante 12 dias, seguida de 1 mês de despolarização, obtiveram, com o processo de tratamento, uma estabiliação no valor de potencial em torno de $-76 \mathrm{mV}$ (ECS). Segundo Yeih e Chang (2005), a razão para esta diferença vem do ambiente. Os experimentos de Elsener (2001) foram realizadas in loco, enquanto os experimentos de Yeih e Chang (2005) foram realizados em laboratório, sob temperatura e umidade ambiental constantes. 
Apesar da diferença entre os resultados de potencial de corrosão em circuito aberto nos estudos acima relatados e no presente trabalho, é importante relatar que o processo de realcalinização tende a aumentar o potencial de corrosão para valores menos eletronegativos. Contudo nem sempre atingindo a condição indicativa de repassivação.

A Figura 11 mostra a relação entre as médias de densidade de corrente de corrosão das armaduras em solução realcalinizada e o período em que a solução ficou carbonatada, após a utilização da técnica de Chauvenet para eliminação de dados espúrios. A partir do ajuste de uma função exponencial, pode-se inferir resultados sobre o estado da barra para as mesmas condições estudadas nesse trabalho. Portanto, pode-se deduzir que o processo de realcalinização pode reestabelecer a condição de nível de corrosão desprezível $\left(>0,1 \mu \mathrm{A} / \mathrm{cm}^{2}\right)$ para até 30 dias de exposição em solução carbonatada e de nível de corrosão baixo $\left(>0,5 \mu \mathrm{A} / \mathrm{cm}^{2}\right)$ para 64 dias de exposição.

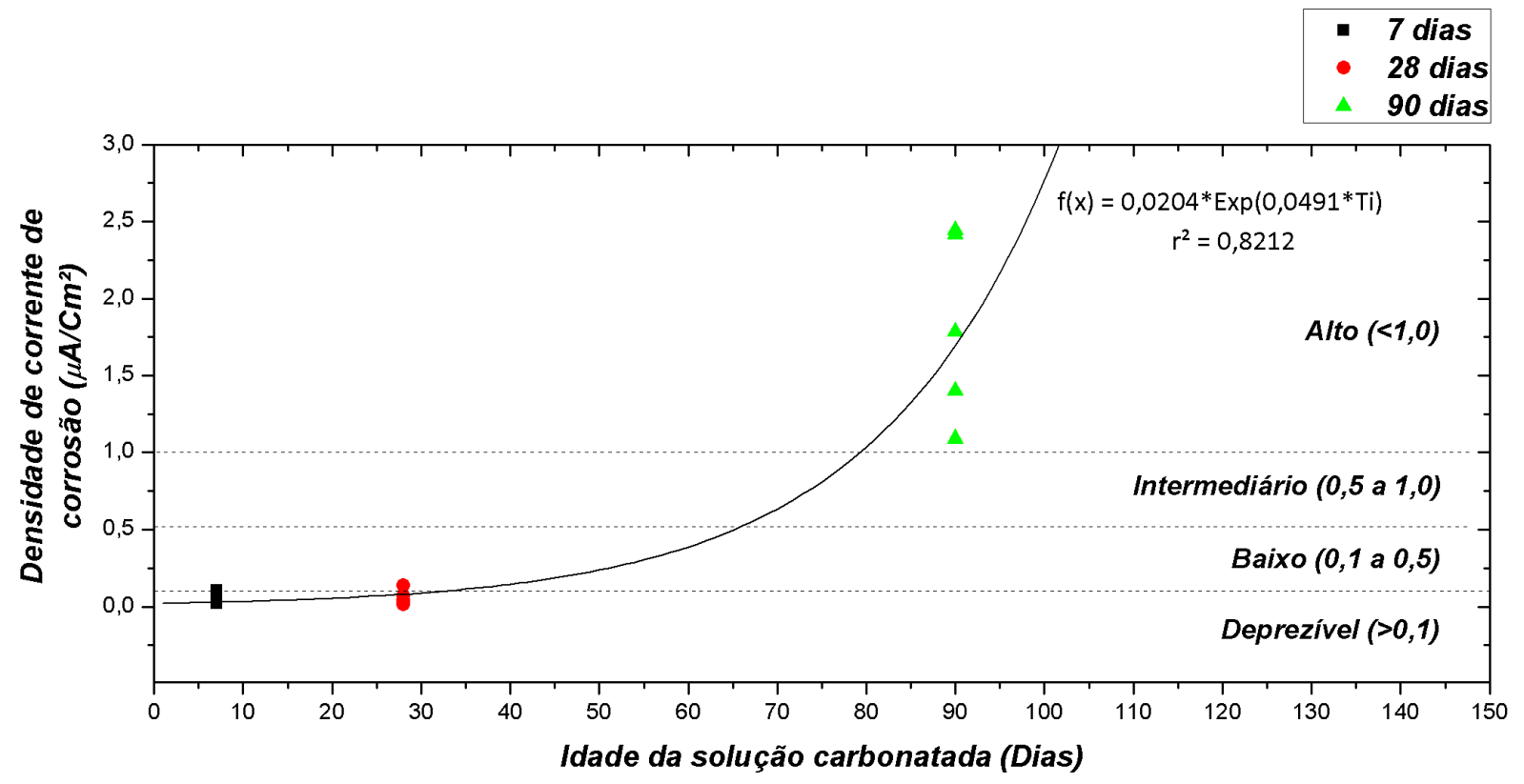

Figura 11: Relação entre a densidade de corrosão e o período em que a solução ficou carbonatada.

\section{CONCLUSÕES}

Considerando-se as condições de ensaio adotadas neste trabalho, pode-se observar que a carbonatação da solução reduziu consideravelmente as leituras de potencial de corrosão e aumentou as leituras de densidade de corrente de corrosão, passando a maioria das barras de um nível de corrosão desprezível para um nível de corrosão alta.

A repassivação da armadura foi observada pelo monitoramento eletroquímico para armaduras expostas até 28 dias em solução carbonatada. Porém, percebe-se, para todos os períodos estudados, que o processo de restabelecimento do $\mathrm{pH}$ em torno da armadura contribui significativamente para o enobrecimento das leituras do potencial de corrosão e redução das medidas de densidade de corrente de corrosão. 
Cabe ainda acrescentar que a repassivação parece depender do tempo de exposição em meio carbonatado e que, mesmo naqueles casos em que a condição de repassivação não é alcançada, observou-se uma eficaz redução na cinética do processo de corrosão, o que pode ser muito interessante para prolongar a vida útil das estruturas em serviço após o processo de realcalinização.

\section{REFERÊNCIAS}

American Society for Testing and Materials. (1999) Standard practice for preparing, cleaning and evaluating corrosion test specimens. ASTM G-1. Annual Book of ASTM Standards. Philadelphia.

Araújo, F. V. C. de. (2009) Estudo da repassivação da armadura em concretos carbonatados através da técnica de realcalinização química. Tese de Doutorado. Escola Politécnica da Universidade de São Paulo.

Bastidas, D. M.; Cobo, A.; Otero, E.; González, J. A. (2008) Electrochemical rehabilitation methods for reinforced concrete structures: advantages and pitfalls. Corrosion Engineering, Science and Technology, 43, 248-255.

Cascudo, O. (1997) Controle da corrosão de armaduras em concreto-Inspeção e Técnicas Eletroquímicas. São Paulo: PINI.

Elsener, B. (2001) Half-cell potential mapping to assess repair work on RC structures. Construction and Building Materials, 15, 2-3.

Kaesche, $H$. (1959) The detection of corrosion danger to steel reinforcement due to admixtures in concrete. Zem.-Kalk-Gips, 12, 289-305.

Mietz, J. (1998) Electrochemical rehabilitation methods for reinforced concrete structures. European Federation of Corrosion Publications, n. 24.

Mehta, P. K.; Monteiro, P. J. M. (2008) Concreto: Microestrutura, propriedades e materiais. Tradutora Cristina Borba. São Paulo: Ibracon.

Miranda, J. M.; González, J. A.; Cobo, A.; Otero, E. (2006) Several questions about electrochemical rehabilitation methods for reinforced concrete structures. Corrosion Science, 48, 2172-2188.

Moreira, C. (2006) Realcalinização de estruturas de concreto carbonatados com a utilização de gel saturado de solução alcalina. Dissertação de Mestrado. Universidade Federal de Goiânia.

Pocock, D. (1994) Chloride extraction and realkalisation - six years on. Corrosion and Protection of Reinforced Concrete, Dubai.

Ribeiro, P.H.L.C.; Meira G.R.; Ferreira, P.R.R.; Perazzo, N. (2013) Electrochemical realkalisation of carbonated concretes - Influence of material characteristics and thickness of concrete reinforcement cover. Construction and Building Materials, 40, 280-290.

Tong, Y. Y.; Bouteiller, V.; Marie-Victorie, E.; Joiret. (2012) Efficiency investigations of electrochemical realkalisation treatment applied to carbonated reinforced concrete - Part 1: Sacrificial anode Process. Cement and Concrete Research, 42, 84-94.

Yeih, W.; Chang, J. J. (2005) A study on the efficiency of electrochemical realkalisation of carbonated concrete. Construction and Building Materials, 19 (7), 516-524. 